\title{
Tales of Disaster: The Role of Accident Storytelling in Safety Teaching
}

\author{
Andrew $\mathrm{Rae}^{\mathrm{a}}$ \\ ${ }^{a}$ Griffith University, Brisbane, Australia \\ School of Humanities, 170 Kessels Rd, Nathan, Qld 4111 Australia \\ d.rae@griffith.edu.au, telephone+61737359764,fax+61737357730
}

Is it appropriate to tell tales about accidents as a form of teaching? Storytelling about accidents is an intrinsic part of safety education, but the role and nature of these stories deserves critical consideration. Even accident reports themselves are reconstructed interpretations of events, and accident stories are at least one step further removed. Knowledge about specific accidents is uncertain, and unsuitable as a learning outcome. However, accident stories play a role in teaching by creating learning experiences through which students can acquire threshold concepts in safety science. The realism of a well-told story, combined with uncertainty and subjectivity surrounding its interpretation, creates an environment that promotes transformative learning. Narrative choices can make the difference between effective storybased teaching and over-simplified hindsight explanations.

Keywords: Safety, Education, Threshold Concepts, Narrative, Case Studies 


\section{$1 \quad$ Start with a Bang}

When I begin a lecture with "On the 2nd May, 1970, a DC-9 operating as flight ALM 980 departed from John F. Kennedy International Airport” my students are immediately aware that the tale is not going to end well. The language introduces a story within the genre of accident reporting, and creates expectations consistent with that genre. Once I have established the scene, the students can expect an inciting event setting up a conflict between the best and worst of human endeavour, followed by a climax where the protagonists (the main characters) are defeated by the antagonists (their real or metaphorical opponents), and probably everybody dies.

The use of real-world examples - in particular storytelling about accidents - is an intrinsic part of safety teaching. Accident case studies are used to motivate and introduce new knowledge, to illustrate theory, and to show how theory can be applied. Why is storytelling such a common feature of safety science and safety engineering programmes? Does this practice have educational value? If so, is this due to the types of students, the subject matter, or some other feature of the programmes? What determines the effectiveness or otherwise of storytelling as a means of safety education?

All accounts of accidents are narratives. A narrative is "a spoken or written text that involves temporal sequences of events and actions" (Maitlis, 2012). The earliest accounts of each accident are witness testimonies, collected by investigators in an evidence gathering process that also collates physical evidence and electronic records. These are typically collated into a single timeline, which guides further investigation and causal analysis, leading to a final report (Johnson, 2003).

In parallel to any official investigations, news media and social media also construct accident narratives. These draw upon official sources and witness testimonies, but often use previous stories and common narrative structures as a framework to assemble partial and uncertain information (Mairal, 2011).

Further narrative accounts are produced when academics study accidents. These revisionist accounts may draw solely on prior narratives, such as Weick's exploration of sense-making in the Mann Gulch fire (Weick, 1993). They may also combine previously separate narratives, as in Leveson's history of the Therac-21 radio-therapy fatalities (Leveson, 1995), or find new primary sources, exemplified by Vaughan's explanation of the Challenger disaster (Vaughan, 2004).

The role and status of accident narratives has been studied in the context of managing reputation (Tyler, 2005), socially constructing risk (Davidson, 2008), setting political priorities (Bergman, Gray, Moffat, Simpson, \& Rivara, 2002; Stone, 1989), organisational learning (Hayes \& Maslen, 2014), and raising safety awareness (Cullen \& Washington, 2007). The common theme linking these diverse uses of accident narratives is one of sense-making about risk. Past experience provides a template for understanding present danger. Sanne (2008) discusses the value and dangers of this phenomenon in the context of railway maintenance workers. For the railway workers, stories were informal, locally relevant, and socially accepted ways to communicate breakdowns in normal work. However, they competed with more systematic and generalizable ways to gather intelligence about potential dangers.

Researchers frequently use accident narratives to form and test new theories of safety. Turner (1976) formulated and explained his theory of Disaster Incubation using the Aberfan tip collapse, the Summerland fire and the Hixon level crossing collision. Perrow (1999) based his theory of Normal Accidents on the Three Mile Island nuclear accident. However, there has been little reflection in the safety research community on the status of narratives as evidence. Safety literature often uses an implicitly positivist framework in which there is an "abstract truth", partially clouded by investigator bias (Woodcock, 2008). Social constructionist accounts of safety, such as those arising from High Reliability Organisations (Rochlin, 1999) set aside accident narratives altogether in favour of studying safety as a positive attribute of organisations.

The broader field of organisational research has been more introspective about its own use of narratives, both as subjects of research and as outputs of the research process (Maitlis, 2012). Here it is recognised that narratives are "socially situated performances" influenced by the narrator, the audience, and the social context of the narrative.

In this paper I will focus on the role of accident narratives in the formal education of safety practitioners. This is a topic that must necessarily be informed by the status of accident narratives as knowledge, but the emphasis will be on the deliberate use of the narratives by a teacher. I will use the term "storytelling" to distinguish this deliberate presentation of a narrative from other narrative texts such as accident reports and media accounts. 
The objective of the paper is to reflect on accident storytelling as a means of teaching safety practitioners. This exploration includes some thoughts on what makes a good accident story, but the emphasis is on how and why teachers tell accident stories. Excellent storytellers are not necessarily students of the art of storytelling. A raconteur may be naturally gifted and make no effort to consciously consider the language or narrative devices they are using. However, good teaching practice demands reflection on the purpose and effectiveness of teaching methods. Teachers who tell stories should not take storytelling for granted.

For a teacher, telling a good story should be a means to an end. A story, whether presented as part of a lecture, as a case study for discussion or as problem-based learning, is a constructed experience to give students the opportunity to acquire knowledge (Herreid, 2007). Well-told stories have educational power.

\section{Give the Protagonist a Goal and Motivation}

Before I can explore the usefulness of stories in safety education, I need to explain my view of what this education is trying to achieve.

Gilbert (2005) suggests that a discipline is defined by the stories it tells about itself. That is certainly true of safety engineering. Any history of safety is structured not around famous safety scientists, the development of compelling theories, or definitive experiments, but around great disasters. We are a discipline forged in the creeping deaths of the industrial revolution, the explosions at Piper Alpha and Bhopal, and the wastelands of Chernobyl.

Some of the characteristics of safety as a field are:

- Safety is inherently interdisciplinary. It draws upon research and practice in management, individual psychology, organisational sociology, engineering and interface design (Aven, 2014).

- The knowledge base of safety is populated mainly from experiences rather than experiments. There are few empirical results, and therefore few certainties (Rae, Nicholson, \& Alexander, 2010).

- Safety activities are often open-loop, with little or no feedback about success and failure (Rae, McDermid, \& Alexander, 2012).

- Safety work products are usually confidential, making it difficult to aggregate data about how safety is practiced (Rae \& Hawkins, 2012).

- The practice of safety engineering is culturally mediated. Attitudes and beliefs can influence outcomes as much, if not more, than the choice of techniques (International Nuclear Safety Advisory Group, 1991).

These characteristics are often summarised by describing safety as requiring "systems thinking" (Leveson, 2011). Systems are not merely physical, merely social, or even some socio-technical combination. The discipline of safety science is itself an interaction between different systems of knowledge (Aven, 2014).

Some safety knowledge is drawn from the physical sciences. This knowledge comes in the form of theories built upon reliably observed phenomena. Other safety knowledge comes from engineering, in the form of models and techniques for predicting the behaviour of designed artefacts. Still more knowledge comes from the social sciences, which provide competing explanations for the behaviour of humans and organisations.

Gilbert (2005), in describing interdisciplinary knowledge, suggest that students “ ... need to know, not the detailed 'facts' of a discipline, but how that discipline 'works' as a system, and how it is different from other systems. They need to know what kinds of problems each system is good at solving, and what kinds of problems might be best solved using another system."

In addition to providing knowledge and technical skills, tertiary education plays an important role in developing professional identity (Dannels, 2000). Previous work on professional identity focuses mainly on undergraduate students, and on the gulf between "academic" engineering and "real" engineering (Katz, 1993). Safety is commonly taught either as a postgraduate programme or as continuous professional development. In each case the students are already practitioners with a professional identity. However, there is still an important element of socialisation in safety education. Programmes don't just teach students how to "do safety"; they teach them how to be safety practitioners.

In part due to this complex knowledge landscape, and in part due to the historical positioning of safety within different industrial disciplines, there is no commonly agreed curriculum for safety education. A useful overview for Europe is provided by Arezes and Swuste (2012), who show that programs use a wide variety of titles, 
accept students from a range of backgrounds, and are hosted in every type of university department. Houdmont (2008) points out the high variability of curriculum even within safety programs sharing the specific title of Occupational Health Psychology.

To the extent that there is such a thing as a "typical" safety education program, it will, based on the Institution of Occupational Safety and Health learning objectives (IOSH, 2013) and the American Society for Safety Engineers curriculum guidelines (ASSE, 2004), contain learning outcomes related to:

- $\quad$ Science and mathematics

- Hazards

- Processes and techniques for assessing risk and treating hazards

- Organisations and management systems

- Theories of accident causation

Programs will often place emphasis on particular types of hazards, with matching science and risk techniques. Some programs will devote most of their attention to hazards and their direct treatment, whilst others will focus almost exclusively on generic risk processes, management, and theory.

Despite this variety in content, the main processes for teaching safety are the same as for any other discipline. Teaching requires selecting a set of knowledge, and creating a sequence of learning experiences through which students engage with that knowledge. The most common way to describe the knowledge to be taught is through a set of learning outcomes describing tasks that a student will be able to perform if they have successfully acquired the knowledge. Learning outcomes are typically phrased as "At the end of this course, students should be able to X”, where X stands for an activity demonstrating competence. For example, learning outcomes on a risk assessment course for safety engineers might include:

- Describe the role of risk assessment in system design

- Compare and contrast qualitative and quantitative risk assessment methods

- Plan and conduct a risk assessment exercise

- Critically review risk assessment reports

Learning outcomes on a more generalist course on safety theory might include:

- Explain current ideas and theories on accident causation

- Apply knowledge of human behaviour in the analysis of accidents and incidents

- Use knowledge of different theories of safety to critique current practice

- Design an organisational safety improvement activity

Despite the centrality of accidents to the discipline of safety, and the common use of accident storytelling to teach safety, specific accidents seldom appear in safety program curricula. Learning outcomes refer to methods to prevent and investigate accidents, and theories to explain accidents, but do not usually consider the accidents themselves to be core knowledge.

There are three resolutions for this paradox. The first is that storytelling is, along with many forms of lecturing, simply a bad habit. The second is that it is that accidents should, in fact, be part of the core curricula of safety education. The third possibility is that disaster storytelling is part of creating a student experience to support the acquisition of knowledge that is not specific to the accidents themselves. This explanation is consistent with the broader social use of accident narratives to make sense of present hazards.

Saleh and Pendley (2012) argue that accident case studies should play a central role in educating engineers about safety. They suggest that historical knowledge about accident mechanisms is core knowledge for engineers. This is similar to the "failure literacy" movement in civil engineering (Delatte, 2010), and the suggestion by Holloway and Johnson (2006) that safety practitioners should make a habit of reading original accident reports in order to avoid myths and misunderstandings, and gain an appreciation of the causal complexity of accidents. Saleh and Pendley also present a learning-process argument, in which accident stories help engineers acquire a multi-disciplinary perspective, and socialise engineers as safety-conscious professionals.

Woodcock (2005) discusses the use of accident narratives in teaching accident investigators. Whilst Woodcock focuses on process, and supports the use of realistic simulations in place of historical accidents, Johnson (2011) lists knowledge of previous incidents as a competency requirement for investigators. Accident case studies are 
also used in Crew Resource Management (CRM) training (O'Connor, 2011). The role of the accidents is motivational - illustrating communication problems that the CRM techniques are designed to avoid.

With the possible exception of accident investigator training, the argument that knowledge of specific accidents is core knowledge for safety practitioners is not compelling. Accident stories may contain information about failure mechanisms, but the tragic occurrence of these mechanisms at a particular time and place is, if viewed simply as content, unnecessary detail. For accident stories to be valuable for education they must have a purpose in helping students attain other learning outcomes.

\section{Create a Believable World}

Meyer and Land (2003) introduce the term "threshold concepts" to describe conceptually difficult notions that open up new, previously inaccessible ways of understanding and interpreting knowledge within a discipline. Examples of threshold concepts provided by Meyer and Land include complex numbers and limits in mathematics, signification and deconstruction in social science, and opportunity cost in economics. Threshold concepts have special status with respect to learning, since they are considered to be transformative and irreversible - they shift the students' point of view in a way that is difficult to unlearn.

The study of threshold concepts within the field of safety has hitherto been limited to a short article by Atherton (2013). Atherton argues that whilst deep understanding of risk is a threshold concept, most health and safety teaching is insufficiently transformative or integrative to convey threshold concepts.

Baillie, Bowden and Meyer (2013) describe the following principles for a curriculum which supports acquisition of threshold capabilities. Students must:

(1) Experience real, previously unseen situations.

(2) Experience variation both within and between situations.

(3) Exercise authentic professional discernment and judgement in each situation.

(4) Reflect on experience (including time out for reflection), and

(5) Have each new experience building on those that came before.

Taken at their most literal, these principles require an authentic experience of organisational life within the classroom in order to teach safety. The timescales, budgets and complexities of real engineering activities make this impossible. However, here the postgraduate nature of safety teaching works in its favour. Both students and instructors bring real-world work experience into the classroom, and the students spend time out of the classroom in safety-critical organisations.

The teaching challenge is to link the classroom to that real world environment such that the students can mentally fill in the missing detail and scale their experiences to create suitable learning situations. This is where stories have an important role in education. They provide the context which translates raw facts and concepts into an experience that students can relate to, understand and remember (Martin \& Brouwer, 1991).

Attempts to describe why stories are effective highlight the difference in role played by a story listener, compared to other listening activities. Stories allow for multiple interpretations and conclusions. Stories "involve a certain level of negotiation in the meaning between teachers and students ... it is the very absence of explicit spelling-out that allows the reader to enter into and engage with the story, triggering the imagination" (Negrete \& Lartigue, 2004).

Knowledge presented as dogma or a series of empirical facts is neither transformative nor irreversible. A passive listener may sometimes acquire new facts, but these can just as easily be unlearned. Deep learning requires becoming actively interested in course content, looking for underlying principles, and relating ideas to previous knowledge and experience (Entwistle, 2000).

\section{Embrace the Audience}

Stories serve a variety of specific educational purposes.

(1) Context - the story provides motive or historical background before a specific concept is introduced 
(2) Interest - the story engages or re-engages listeners into the learning session, without accomplishing any content-specific teaching outcome

(3) Importance - the story underscores a concept, typically by showing what can go wrong if it is ignored

(4) Authority - the story serves as evidence for the truth of a concept

(5) Realism - the story helps the listener imagine themselves needing and applying the concept

Each purpose requires some degree of immersion within the story, which implies submission to the authority of the storyteller. McCloskey describes this challenge within the field of economics:

"A scientist convinced of what she writes will come from a certain background, supplied with a language. Unless her reader knows roughly the same language - that is, unless he has been raised in approximately the same conversation he will misunderstand and will be unpersuaded ... We do not submit to the authorial intentions of a badly done greeting card. In a well-done novel or a well-done scientific paper we agree to submit to the authorial intentions, so far as we can make them out. The entire game in a science such as biology or chemistry or economics is to evoke this submission to authorial intentions" (McCloskey, 1990).

\subsection{Stories for the Purpose of Context and Interest}

“On 23rd February, 1995, a Boeing 747-400 took off from East Midlands Airport headed for Lanzarote. Shortly after take-off both engines showed a sudden drop in oil pressure, and the flight diverted for Luton. The engines shut down due to a lack of oil during the landing roll. The proximate cause of this near-tragedy was that the high-pressure rotor covers were missing from both engines. Why were they missing? Let's go back to the night maintenance shift on the previous evening..."

This story goes on to describe the events of the evening as a series of bad decisions, including mistakes, casual non-compliances and active rule breaking. I then ask the students "Who is responsible for the accident?" and after a brief discussion assert that this is an example of an "organisational accident". The next portion of the lecture formally introduces the concept of organisational accidents, and explains how it relates to other concepts that the students are already familiar with, such as "systematic failures" and the "Swiss Cheese Model". The story is then re-told from the perspective of the new concept, adding details that shift the focus of the story away from the actions of individuals and towards failings of the organisation.

This style of storytelling is known as a "perspective shift" or "perspective reversal" where the interpretation of actions in a story changes when the same scene is recounted from a different point of view.

The purpose here is to provide a realistic setting in which the concept of "organisational accidents" can be explained. Different parts of the concept can be illustrated using examples from the story, and students can phrase questions in terms of the story or the theory as they try to make sense of the concept. The ultimate learning outcome is for students to be able to "compare and contrast behavioural and organisational theories of accident causation".

I often open a lecture with an accident story to provide context and arouse interest. A review of my own lecture material indicated that it is my second most common way of opening a lecture - the most common is to position the learning outcomes relative to other parts of an engineering lifecycle.

\subsection{Stories for the Purpose of Importance and Authority}

Whereas a story told before introducing a concept provides context, a story told after the concept is introduced reinforces the concept and provides alternate ways of understanding it. The following story is part of a lecture about reporting systems. At this point in the lecture I have already described the importance of clear rules, confidentiality, predictable consequences for bad actions, and regularly exercised communication channels.

"Back around the year 2000 Danish air traffic authorities were struggling with a series of loss of separation incidents - 'loss of separation' is air traffic management jargon for when two aircraft almost hit each other. These incidents weren't being reported through regular channels, mainly because of a fear of prosecution. On a number of occasions incidents were covered up, and then leaked to the press, who demanded blood, resulting in prosecutions, resulting in more cover-ups. They introduced a system with four simple, absolute rules.

Rule 1: Breaking confidentiality will get you punished. 
Rule 2: If you report an incident, you are guaranteed confidentiality and immunity.

Rule 3: The only exceptions to rule 2 are gross negligence and drug taking

Rule 4: If you don't report an incident, but the other party does, we throw the book at you.

Can you see the likely effect of these rules? Previously, if you thought you might be blamed for an incident, the best thing to do was to keep your mouth shut. Even if it wasn't your fault, there was nothing to gain and everything to lose by talking about it. Now, speaking out gets you immunity. The main thing to be scared of is if you don't report but somebody else does."

The story goes on to explain how the change in policy led to a dramatic change in the reporting culture and behaviour. The flood of new data was difficult to cope with, but eventually identified technical problems with the airport equipment that weren't the fault of the air traffic controllers at all, and which wouldn't have been identified without their co-operation in reporting. The learning outcome is for students to be able to "explain the relationship between just culture and organisational improvement."

Stories such as this have little scientific weight in supporting the concept, but they have a lot of emotional pull. They reinforce both the importance of the concept, and the persona of the lecturer as someone who understands the challenges that real practitioners face.

\subsection{Stories for the Purpose of Realism}

A student has not fully attained a concept until they have had a chance to apply it themselves and relate it to their own experiences. Such exploration also provides an opportunity to consider variations on the concept, and evaluation of the scope in which it is and is not applicable. A lecture format is not well suited to these activities, so the use of storytelling must extend to individual study and group-work.

Herreid defines cases studies as "stories with an educational message", and describes their use across lectures, discussions, and practical problem exercises. "If reading, arguing, and challenging are hallmarks of critical thinking, then case studies are the poster children for the process. Most of them are discipline specific, certainly. But they all grapple with the essence of critical thinking - asking for evidence-developing a habit of mind that should permeate everyday life." (Herreid, 2004).

The following extract is part of an "interrupted case study" (Herreid, 2007) dealing with a modification to a fictional aircraft, the Mistrale. The case study follows a lecture on change management during through-life safety.

"SafeAir decide to offer the modification to their overseas suppliers as an optional change, at cost, since it does not directly affect safety. Most of the customers decline the offer. One of the Asian customers, the Air Force of Indo-Amnesia (AFIA), asks to buy one copy of the pack in order to try out the change, to see if it is worthwhile implementing on the rest of their fleet. What problems might arise because of this? Should SafeAir accept the request?"

This case study presents the students with a closed-question decision task ("Should SafeAir accept the request?") intended to provoke discussion and debate. The information provided is intentionally insufficient and ambiguous - most student groups raise questions that cannot be answered. The role of the instructor is to reflect these questions back to the group, helping them to recognise that in real world situations there would be no definitive response to their desire for more factual information, and that decisions must be made in the face of this uncertainty. The learning outcome is for students to be able to "apply the principles of through-life safety to make operational decisions."

\section{Drive Plot with Conflict}

Storytelling is not perfectly aligned with the principles of threshold concepts and deep learning. One area where stories fall short is in the critical examination of argument and evidence. Stories are not evidence, and arguably teaching-by-storytelling places anecdotes in a privileged position ahead of critical analysis.

Stories include plots, which convey temporality and causality (Carter, 1993), but many approaches to safety scholarship reject linear causal explanations of accidents (Dekker, Cilliers, \& Hofmeyr, 2011; Hollnagel \& Goteman, 2004; Lundberg, Rollenhagen, \& Hollnagel, 2009). Others have argued for renewed scientific rigour 
in safety research (Alexander, Rae, \& Nicholson, 2010). It is hard to reconcile storytelling with either complexity or scientific rigour.

Every story has a lifecycle. A story is born before it is told, and it does not die in the telling. The story of an accident starts with media reporting in the immediate aftermath of a real world event, and grows through official investigation and expert analysis. At some point after an accident the teacher must learn the story. This may be by reading the primary source, but it is more likely that the teacher will first encounter the story as told by someone else. The story may be told for general consumption as a documentary or mass-market non-fiction, or it may be included within more scholarly texts. Johnson and Holloway describe the dangers of acquiring safety stories in this way (Holloway \& Johnson, 2006). They warn that storytelling can create and perpetuate myths and misunderstandings about specific accidents and about accidents in general. Holloway and Johnson are particularly concerned that stories may rely on simplistic explanations and black-and-white characters.

Once they are detached from their source material, stories may grow and change. What was speculation in the original report may become fact in retelling. Small details critical to understanding motives and actions may be lost, casting the actors in better or worse light.

Embracing the uncertain relationship between discourse and reality is a threshold concept in social science (Edwards, Ashmore, \& Potter, 1995). Falsifiability and updating beliefs in the face of evidence are central to understanding the physical sciences. Teaching students to be safety practitioners requires training them in both modes of scientific thought.

This does not mean that learning about safety can or should involve constant scientific thinking. Before a student can engage in scientific thought they need to imagine themselves in a scientific role (Gilbert et al., 2005). Here is the promise and the danger. Storytelling can enable the context required for engagement, but inappropriate use of storytelling may teach students unscientific habits of thought and practice.

\section{Deliver what you Promise}

Recognition of the role, promise, and danger of storytelling is a step towards better safety teaching. It allows examination of the type of stories that are used, and the way they are told. This is where narrative theory has something to offer to the practical teacher.

"Why narrative appeals, how the storyteller tells her story, what keeps us turning the page, how we recognize what is important for the narrative (need-to-know as opposed to nice-to-know), must be the concern of theoretician and practitioner alike" (Hunt, 1990)

In other words, theory can help determine what makes a good story, and how to tell that story well. Telling a good story well is a necessary but not sufficient condition for teaching. Success will be measured based on the story's effectiveness in providing learning experiences.

Storytellers make choices. Some choices will influence the overall quality of the story. If a narrator breaks the styles and conventions of genre, for example, the listener is likely to feel tricked and "fall out of the story". No learning outcome will be accomplished. Similarly, if there is inadequate conservation of detail - introducing information unnecessary for the atmosphere or plot - it becomes harder for the listener to recognise and achieve the learning outcome. Anton Chekhov is credited with the principle of "Chekhov's Gun":

"Remove everything that has no relevance to the story. If you say in the first chapter that there is a rifle hanging on the wall, in the second or third chapter it absolutely must go off. If it's not going to be fired, it shouldn't be hanging there." (TVTropes, 2013)

Other choices will influence both the quality of the story and the message of the story. In particular, choices relating to characters and points of view create valence - they help the listener relate emotionally to aspects of the story. Choices relating to plot points - particularly timing of when details emerge - help the listener infer causal relationships.

\subsection{Placement of Main Plot Points}

In a conventional narrative arc, there are two events, or "story beats", of particular significance. The "inciting incident" changes life as it is, setting a conflict into place. The "crisis" resolves the conflict and establishes a new equilibrium (McKee, 2010). 
In an accident story, there are two natural candidates for these events: the accident itself, and the identification of the causes. The accident can be the inciting incident, arcing towards the final revelation of the causes. This creates a clear conflict requiring resolution - the classic mystery or police procedural conflict between perpetrator and investigators.

One potential difficulty is that the accident itself may unfold over a significant period of time. This isn't insurmountable - there is room in the plot arc for a midpoint or "first crisis", secondary to the main crisis. "The heroes emerge safely from the accident, but now they must embark on a new struggle, to find the answers." This only compounds the second difficulty, though, which is that placing the cause of the accident at the crisis is very poor safety engineering pedagogy. Students should not be led to believe that accidents can be ascribed single, simple causes. The explanation for an accident should be unsatisfactory, encouraging a constant quest for deeper understanding.

A much better fit is to place the earliest causal factor in the accident as the inciting incident. The plot arc then leads through the development of failures and mistakes until it eventually reaches the accident event. If the accident occurs over an extended period of time, the start of the accident becomes a first-crisis midpoint.

Placing an accident at the crisis means that the antagonist wins the conflict. This is counter to most narrative conventions, but is acceptable if we accept that disaster stories are a genre, and that failure at the crisis is a convention of the genre. There is an obligation to make the genre clear to the listener at an emotional level so that the story fulfils its promises. One way to achieve this is through the language of the scene-setting before the inciting event. This explains the standardised language opening most disaster stories. Once the listener is primed to expect a particular genre, a failure by the heroes will not be unexpected. Narrow escapes are acceptable, but serve as unexpected plot twists, playing with the conventions of the genre.

\subsection{The Protagonist, Antagonist, and Conflict}

Every plot requires a protagonist. The protagonist is on a physical or metaphorical journey towards some goal. If the protagonist must become a different or better person before they can reach the goal, they undergo character development. Obstructing the path to the goal is an antagonist. The antagonist has goals that are inconsistent with the goals of the protagonist. The nature of the conflict between the antagonist and the protagonist determines the basic plot structure (McKee, 2010).

Whilst it may seem that the antagonist in a disaster plot is the disaster itself, natural forces are not invested with agency; they have no goal. A disaster movie will frequently establish other humans - selfish or wilfully blind as the antagonists. A teaching experience cannot afford such easy blame (Dekker, 2011). The antagonist - and therefore the conflict - must be internal, facilitating understanding of why decisions were made, even if in hindsight they appear to be errors.

Northrop Frye (1957) proposes a theory of "modes" characterising the protagonist. He asks about the moral character and power of the protagonist. Is the protagonist morally better than us, worse than us, or on the same level as us? Are they capable of more than a normal person, the same as a normal person, or are they unusually limited in intelligence or influence? Whilst Frye's model extends to stories where the hero has power above and beyond natural law, it also provides insight into how humans are portrayed. A storyteller can choose for the protagonists to be heroic examples, influential but misguided, helpless victims, or a tragic cause of their own misfortunes.

Telling a disaster story from the perspective of the victims is very common in media depictions of accidents. The effect is to highlight the sequence of events after the accident becomes highly likely or inevitable, and to decrease the importance of the long term causes of the accident.

Victim-based narratives are frequently paired with investigator-based stories. Where this happens, it is often portrayed as a search for "the explanation" for what has caused the awful experience for the victims.

For safety students, victim stories promote learning outcomes relating to ethics. They highlight that the ultimate responsibility of the practitioner is to the safety of the public. The victim appears both innocent and powerless, reinforcing both the power of the safety practitioner, and the importance of exercising that power morally. 
The first and most obvious rule of a victim narrative is not to blame the victim. The power of the story comes from the audience viewing the victim as an eligible target of moral consideration - ideally a vulnerable innocent. Mistakes must be explained by the situation, not by stupidity.

"The Piper Alpha workers had been told to assemble in the accommodation blocks in the event of an emergency. Their training led them to believe that this was the safest place to be whilst waiting for rescue. They were unaware that the location of the fire, the direction of the wind, and the lack of alternate evacuation routes would turn this safe-haven into a death-trap."

By making the experience of an accident vivid and realistic, victim stories also make accidents more salient.

An investigator protagonist story is similar, but not identical, to a classic mystery story. A brilliant classic mystery provides all of the elements necessary for the audience to solve the mystery, and then entertains by providing a solution that the audience did not expect. The cleverness of the solution (and therefore the cleverness of the detective) provides a climax for the story.

For educational purposes, it is helpful for the students to discover the solution for themselves, before it is revealed. Making logical connections between pieces of evidence, followed by the positive feedback of being right, is more effective than the students being surprised by the solution.

As each detail emerges, the students can fit it into a broader picture. Occasionally this picture will be imperfect, so an investigator story must contain reconciliation points. These are often presented in the guise of "recaps".

"So at this point, what did the investigators know? The witness testimony and evidence from the flight recorder told them that the pilots had not deliberately or accidentally triggered the ejector seat. The test and inspection evidence told the investigators that the seat was working correctly two days before the accident. It was clear that something had gone wrong during those two days. They set out to trace exactly what had happened ..."

An investigator-protagonist story relies heavily on flashbacks. Whilst the story is nominally set after the accident, this is in fact a framing device to tell the story of what happened before the accident. The accident remains at the climax of the story, but paradoxically also becomes the initiating event - the first sign that something is wrong. Told in this way there is no single clear explanation as in a classic mystery, just a realisation that all of the preceding events contributed to the accident.

In science education, one of the challenges is that students see a gap between themselves and the "geniuses" who make scientific discoveries (Gilbert et al., 2005). Safety engineering education has the reverse problem students find it hard to relate to the apparently poor behaviour of engineers and managers involved in accidents. One of the goals of storytelling is to show how hard it was for the protagonists to make the right decision with the information they had available. If the moral of the story is too simplistic and if the right answer appears too obvious, any complexity in the learning outcome will be lost.

An operator-protagonist story makes heavy use of foreshadowing, with the rule of Chekhov's Gun in constant play. The student can simultaneously understand the reasons for an action at the time, and the possible eventual consequences of that action.

"There was a simple solution to the exact problem - an operator controlled backup called the block valve. If the operators closed the block valve, steam would stop escaping, and the reactor would be in its normal shutting down state. Shutting the block valve wasn't a general solution to any problem though - it was a specific solution to a stuck-open PORV valve. Before the operators could implement this as a solution, they needed to understand the problem.

This is the point where it would be very helpful for the operators to have a little light that told them whether the PORV was open or closed. There was indeed a light that they thought provided this information. The light was turned on and off by the power to the valve, rather than by the valve positions directly. They thought it was telling them that the valve was closed, when in fact it was merely telling them that the valve was meant to be closed. With the valve stuck open, a loss of coolant accident was in progress." 


\subsection{Timing}

As well as the placement of plot points and the choice of protagonist, a storyteller must make a series of decisions about the order of events. The first such decision relates to temporal framing. When does the story start? When does it finish? Framing can include and exclude details from the plot. Typically an earlier start will broaden the causes of the accident, including aspects of organisational culture, regulation, and political decisionmaking. A later start will focus on technical and operational causes of the accident. What order is used to convey events? In a story, time and order are proxies for causality. If event A is followed immediately by event $\mathrm{B}$, it is implied that event A made event B more likely. The storyteller is not restricted by the order in which events actually happened. "Foreshadowing" can introduce future events early, by hinting at what is to come. A "reveal" can hide a detail until it becomes relevant, changing perceptions of causality by re-ordering events within the story without changing the underlying timeline.

\section{$7 \quad$ Make your Characters Vulnerable}

This paper is written in first person as a deliberate narrative choice. It is part of a story that began when I asked myself the question "Why do I tell so many tales about accidents?" The conflict that drove the plot was the tension between my role as a storyteller and my professional identity as a safety engineer. Real science is about falsifiable hypotheses tested by empirical investigations, isn't it? Maybe I shouldn't be telling stories at all.

Like any protagonist obedient to the demands of plot and genre, I set out on a journey. I encountered characters such as Holloway and Johnson (2006) warning me of the dangers of embracing story, and Gilbert (2005) suggesting that story was the only path to reach my goals. The climax of the story was reached, and the conflict resolved, when I attained the threshold concept (Meyer \& Land, 2003) that all teaching is storytelling. Crafting student experiences through tales is not only desirable but also unavoidable. The challenge is to align storytelling with learning outcomes through appropriate narrative choices.

Just as poor accident reports can be instruments of blame that hinder the process of community learning, poorly constructed stories can lead students away from desirable learning outcomes. Good stories, told well, lead students toward fresh insights and deep understanding.

Alexander, R. D., Rae, A. J., \& Nicholson, M. (2010). Matching Goals and Methods in System Safety Engineering.

Arezes, P. M., \& Swuste, P. (2012). Occupational Health and Safety post-graduation courses in Europe: A general overview. Safety Science, 50(3), 433-442. http://doi.org/10.1016/j.ssci.2011.10.003

ASSE. (2004). Safety Curriculum Guidelines. Retrieved April 9, 2015, from

http://www.asse.org/professionalaffairs/govtaffairs/ngposi18/

Atherton, J. S. (2013). Health and Safety and threshold concepts. Retrieved November 10, 2014, from http://www.doceo.co.uk/tools/TC_HandS.htm

Aven, T. (2014). What is safety science? Safety Science, 67, 15-20. http://doi.org/10.1016/j.ssci.2013.07.026

Baillie, C., Bowden, J. A., \& Meyer, J. H. F. (2013). Threshold capabilities: threshold concepts and knowledge capability linked through variation theory. Higher Education, 65(2), 227-246. http://doi.org/10.1007/s10734012-9540-5

Bergman, A., Gray, B., Moffat, J., Simpson, E., \& Rivara, F. (2002). Mobilizing for pedestrian safety: an experiment in community action. Injury Prevention, 8(4), 264-267. http://doi.org/10.1136/ip.8.4.264

Carter, K. (1993). The Place of Story in the Study of Teaching and Teacher Education. Educational Researcher, 22(1), 5-18. http://doi.org/10.3102/0013189X022001005

Cullen, E. T., \& Washington, S. (2007). Tell Me A Story... Using Stories to Improve Occupational Safety Training. Proceedings of ASSE's Safety 2007, Orlando, FL, USA.

Dannels, D. P. (2000). Learning to Be Professional: Technical Classroom Discourse, Practice, and Professional 
Identity Construction. Journal of Business and Technical Communication, 14(1), 5-37. http://doi.org/10.1177/105065190001400101

Davidson, L. (2008). Tragedy in the Adventure Playground: Media Representations of Mountaineering Accidents in New Zealand. Leisure Studies, 27(1), 3-19. http://doi.org/10.1080/02614360701240972

Dekker, S. (2011). The criminalization of human error in aviation and healthcare: A review. Safety Science, 49(2), 121-127. http://doi.org/10.1016/j.ssci.2010.09.010

Dekker, S., Cilliers, P., \& Hofmeyr, J.-H. (2011). The complexity of failure: Implications of complexity theory for safety investigations. Safety Science, 49(6), 939-945. http://doi.org/10.1016/j.ssci.2011.01.008

Delatte, N. (2010). Failure literacy in structural engineering. Engineering Structures, 32(7), 1952-1954.

Edwards, D., Ashmore, M., \& Potter, J. (1995). Death and Furniture: the rhetoric, politics and theology of bottom line arguments against relativism. History of the Human Sciences, 8(2).

Entwistle, N. (2000). Promoting deep learning through teaching and assessment: conceptual frameworks and educational contexts.

Frye, N. (1957). Anatomy ofcriticism. Princeton: Princeton UP.

Gilbert, J., Hipkins, R., \& Cooper, G. (2005). Faction or fiction: Using narrative pedagogy in school science education (Vol. 30).

Hayes, J., \& Maslen, S. (2014). Knowing stories that matter: learning for effective safety decision-making. Journal of Risk Research, 1-13. http://doi.org/10.1080/13669877.2014.910690

Herreid, C. F. (2004). Can case studies be used to teach critical thinking? Journal of College Science Teaching, $33(6), 12-14$.

Herreid, Clyde Freeman. 2007. Start with a Story: The Case Study Method of Teaching College Science. NSTA Press.

Hollnagel, E., \& Goteman, O. (2004). The functional resonance accident model. Cognitive System Engineering in Process Plant 2004.

Holloway, C. M., \& Johnson, C. W. (2006). Why System Safety Professionals Should Read Accident Reports. Presented at the IET System Safety Conference, London. Retrieved from http://archive.org/details/nasa_techdoc_20060020178

Houdmont, J., Leka, S., \& Bulger, C. (2008). The Definition of Curriculum Areas in Occupational Health Psychology (Vol. 3, pp. 145-170). Nottingham, UK: Nottingham University Press. Retrieved from http://eprints.nottingham.ac.uk/960/

Hunt, P. (1990). New Directions in Narrative Theory. Children's Literature Association Quarterly, 15(2), 4647. http://doi.org/10.1353/chq.0.0809

International Nuclear Safety Advisory Group. (1991). Safety Culture. Vienna.

IOSH. (2013). Accreditation of Qualifications.

Johnson, C. (2003). Failure in Safety Critical Systems: A Handbook of Accident and Incident Reporting. Glasgow: University of Glasgow Press.

Johnson, C. (2011). Competency management systems to support accident and incident investigators. Las Vegas. Retrieved from http://www.dcs.gla.ac.uk/ johnson/papers/ISSC2011/investigator_training.pdf

Katz, S. M. (1993). The Entry-Level Engineer: Problems in Transition from Student to Professional. Journal of 
Engineering Education, 82(3), 171-174. http://doi.org/10.1002/j.2168-9830.1993.tb00097.x

Leveson, N. (1995). Medical Devices: The Therac-25. Addison Wesley.

Leveson, N. (2011). Engineering a Safer World. MIT Press.

Lundberg, J., Rollenhagen, C., \& Hollnagel, E. (2009). What-You-Look-For-Is-What-You-Find - The consequences of underlying accident models in eight accident investigation manuals. Safety Science, 47(10), 1297-1311. http://doi.org/10.1016/j.ssci.2009.01.004

Mairal, G. (2011). The history and the narrative of risk in the media. Health, Risk \& Society, 13(1), 65-79. http://doi.org/10.1080/13698575.2010.540313

Maitlis, S. (2012). Narrative Analysis. In G. Symon \& C. Cassell (Eds.), (pp. 492-511). Los Angeles: Sage Publications.

Martin, B. E., \& Brouwer, W. (1991). The sharing of personal science and the narrative element in science education. Science Education, 75(6), 707-722. http://doi.org/10.1002/sce.3730750610

McCloskey, D. N. (1990). Storytelling in economics. Narrative in Culture: The Uses of Storytelling in the Sciences, Philosophy, and Literature, 5-22.

McKee, R. (2010). Story: Style, Structure, Substance, and the Principles of Screenwriting (1st Edition). HarperCollins.

Meyer, J., \& Land, R. (2003). Threshold concepts and troublesome knowledge: linkages to ways of thinking and practising within the disciplines. University of Edinburgh UK.

Negrete, A., \& Lartigue, C. (2004). Learning from education to communicate science as a good story. Endeavour, 28(3), 120-124. http://doi.org/10.1016/j.endeavour.2004.07.003

O'Connor, P. (2011). Assessing the Effectiveness of Bridge Resource Management Training. The International Journal of Aviation Psychology, 21(4), 357-374. http://doi.org/10.1080/10508414.2011.606755

Perrow, C. (1999). Normal Accidents: Living with High-Risk Technologies. Princeton University Press.

Rae, A. J., \& Hawkins, R. (2012). Risk Assessment in the Wild. Presented at the Australian Safety Critical Systems Conference, Brisbane.

Rae, A. J., McDermid, J., \& Alexander, R. D. (2012). The Science and Superstition of Quantitative Risk Assessment. Presented at the Annual European Safety and Reliability Conference, Helsinki.

Rae, A. J., Nicholson, M., \& Alexander, R. D. (2010). The State of Practice in System Safety Research Evaluation. Presented at the IET System Safety Conference, Manchester.

Rochlin, G. I. (1999). Safe operation as a social construct. Ergonomics, 42(11), 1549-1560.

Saleh, J. H., \& Pendley, C. C. (2012). From learning from accidents to teaching about accident causation and prevention: Multidisciplinary education and safety literacy for all engineering students. Reliability Engineering \& System Safety, 99, 105-113. http://doi.org/10.1016/j.ress.2011.10.016

Sanne, J. M. (2008). Incident reporting or storytelling? Competing schemes in a safety-critical and hazardous work setting. Safety Science, 46(8), 1205-1222. http://doi.org/10.1016/j.ssci.2007.06.024

Stone, D. A. (1989). Causal Stories and the Formation of Policy Agendas. Political Science Quarterly, 104(2), 281-300. http://doi.org/10.2307/2151585

Turner, B. A. (1976). The Organizational and Interorganizational Development of Disasters. Administrative Science Quarterly, 21(3), 378-397. http://doi.org/10.2307/2391850 
Tyler, L. (2005). Towards a postmodern understanding of crisis communication. Public Relations Review, 31(4), 566-571. http://doi.org/10.1016/j.pubrev.2005.08.017

Vaughan, D. (2004). Theorizing Disaster: Analogy, historical ethnography, and the Challenger accident. Ethnography, 5(3), 315-347. http://doi.org/0.1177/1466138104045659

Weick, K. E. (1993). The Collapse of Sensemaking in Organizations: The Mann Gulch Disaster. Administrative Science Quarterly, 38(4), 628-652. http://doi.org/10.2307/2393339

Woodcock, K. (2008). Content analysis of 100 consecutive media reports of amusement ride accidents. Accident Analysis \& Prevention, 40(1), 89-96. http://doi.org/10.1016/j.aap.2007.04.007

Woodcock, K., Drury, C. G., Smiley, A., \& Ma, J. (2005). Using simulated investigations for accident investigation studies. Applied Ergonomics, 36(1), 1-12. http://doi.org/10.1016/j.apergo.2004.10.002 